\title{
EFEITOS DO USO DE TI MÓVEL EM SALA DE AULA
}

EFFECTS OF USE OF MOBILE IT IN A CLASSROOM

Recebido em 28.11.2018. Aprovado em 27.02.2019

Avaliado pelo sistema double blind review

Jackson Soares de Carvalho

DOI: http://dx.doi.org/10.12712/rpca.v13i1.27437

pahiaky@gmail.com

Universidade Federal de Rondônia - Rondônia, Brasil

ORCID: https://orcid.org/0000-0003-4552-4150

\section{Deyvison de Lima Oliveira}

deyvilma@gmail.com

Professor da Universidade Federal de Rondônia -Rondônia, Brasil

ORCID: https://orcid.org/0000-0001-6984-6520.

\section{José Arilson de Souza}

professorarilson@,hotmail.com

Professor da Universidade Federal de Rondônia - Rondônia, Brasil

ORCID: https://orcid.org/0000-0002-8416-9529.

\section{Elder Gomes Ramos}

ramos.elder@gmail.com

Professor da Universidade Federal de Rondônia- Rondônia, Brasil

ORCID: https://orcid.org/0000-0003-3664-6172.

\section{Resumo}

Nas instituições de ensino superior, a Tecnologia da Informação (TI) móvel é utilizada para tarefas previstas no plano de ensino e para atividades sem relação alguma com a aula. Este artigo buscou identificar os efeitos negativos do uso de TI móvel pelos discentes em sala de aula. Para tanto, os procedimentos metodológicos de coleta de dados consistiram em observação direta e em entrevistas com docentes e com um grupo focal com discentes. Para a análise dos dados coletados, adotou-se a análise de conteúdo. Por meio de levantamento bibliográfico, foi possível identificar 14 efeitos negativos da TI sobre os usuários. Na percepção dos entrevistados, 13 desses efeitos têm impacto significativo sobre os usuários. Os docentes e discentes participantes da pesquisa acreditam que o futuro da educação passa por uma presença ainda maior da tecnologia e que os efeitos negativos disso devem ser conhecidos para que sejam minimizados, melhorando, a qualidade do ensino.

Palavras-chave: Efeitos negativos. Tecnologia. Ensino.

\section{Abstract}

In higher education institutions, mobile information technology (IT) is used for tasks foreseen in the teaching plan and for activities with no relation to the class. This article aimed to identify the negative effects of the use of mobile IT by students in the classroom. For that, the methodological procedures of data collection consisted of direct observation and interviews with teachers and with a focus group with students. For the analysis of the collected data, the content analysis was adopted. Through a bibliographical survey, it was possible to identify 14 negative effects of IT on users. In the perception of the interviewees, 13 of these effects have a relevant impact on the users. The teachers and students participating in the research believe that the future of education is an even greater presence of technology and that the negative effects of this must be known in order to be minimized, improving the quality of teaching.

Keywords: Effects negatives. Technology. Teaching. 


\section{Introdução}

O contexto brasileiro é marcado, atualmente, por um processo de ampliação do ensino superior e da pósgraduação, processo esse que se intensificou nas duas últimas décadas (Rangel \& Miranda, 2016). Concomitantemente a essa ampliação, o uso da Tecnologia da Informação (TI) tem crescido de forma consistente (Meireles, 2016). De acordo com dados da Fundação Getúlio Vargas (FGV), no Brasil, existem 244 milhões de dispositivos móveis (notebooks, tablets e smartphones) conectáveis à internet - o que perfaz o impressivo número de 1,2 dispositivo por habitante.

De fato, o uso de TI móvel está cada vez mais presente no dia a dia das pessoas. Segundo o Instituto Brasileiro de Geografia e Estatísticas (IBGE), em 2013, o acesso à internet pelo celular era hábito de 53,6\% dos usuários, número que, em 2014, passou a $80,4 \%$, o que representa um crescimento de $26,8 \%$ em um ano. Também de acordo com dados do IBGE, a Pesquisa Nacional por Amostra de Domicílios (Pnad) de 2014 revelou que 54,9\% das casas brasileiras contam com acesso à rede de computadores e existem mais pessoas acessando a internet pelo celular do que pelo computador $(76,6 \%)$. Pela primeira vez, dados do Pnad apontaram para um uso da internet pelo celular superior ao uso no computador.

Diante desse contexto, surgem questões sobre o impacto desses novos hábitos na educação. De acordo com Shuler, Winters e West (2014), na obra O futuro da aprendizagem móvel, nas próximas décadas, parece evidente que a educação ocorrerá num mundo ainda muito mais conectado, com tecnologia mais barata e acessível. Emerge, assim, a necessidade de as instituições de ensino superior se adequarem às mudanças e melhorarem os processos de formação de futuros profissionais (Rangel \& Miranda, 2016).

Segundo Moura (2012), o acesso a conteúdo multimídias não está ligado a somente um microcomputador; de fato, conforme já adiantado, as tecnologias móveis vêm tomando espaço, o que cria um novo paradigma educacional: o mobile learning ou a "aprendizagem móvel". Os trabalhos exploratórios de Oliveira e Simões (2016) e Rangel e Miranda (2016) identificaram alguns impactos do uso da TI móvel pelos discentes. Em alguns construtos, o uso da TI não influenciou o desempenho e, em outros, a influência foi positiva. Contudo, com esses hábitos, o docente está sendo impactado indiretamente, o que pode ter efeitos negativos no ensino. Os autores aventam também a possibilidade de que os discentes não se apercebam de tal impacto, pois o uso constante da TI não os permite comparar o seu desempenho àquele que aconteceria sem o uso da internet (Oliveira \& Simões, 2016).

Por um lado, inúmeras pesquisas vêm tentando mapear os fatores determinantes do desempenho acadêmico (Miranda et al, 2015), concluindo que a identificação dessas variáveis poderia ser um caminho para se aprimorar a educação brasileira. Por outro lado, pouco se tem estudado sobre os efeitos do uso de TI móvel pelos discentes nas salas de aula, espaço no qual o professor figura como um agente passivo do uso dessas tecnologias.

Os estudos na área de Sistemas de Informação buscam identificar, predominantemente, os efeitos positivos da TI móvel sobre os fenômenos que cercam seus usuários (e.g. aprendizagem, desempenho acadêmico etc.), inclusive as pesquisas supracitadas. Contudo, são evidentes na literatura os indícios de efeitos negativos da TI sobre os indivíduos e organizações, a exemplo da distração digital e no trabalho (Cappellozza, Morais \& Muniz, 2017). Nesta linha, tendo em vista o uso intenso de TI móvel no espaço universitário, o objetivo deste artigo é identificar alguns dos efeitos negativos do uso de TI móvel pelos discentes em sala de aula em uma universidade federal.

\section{Referencial Teórico}

Nesta seção, serão apresentados aspectos conceituais de TI móvel, de redes sociais e de aplicativos móveis. Serão abordados também o uso da TI na educação e os efeitos negativos da TI nas pessoas.

\section{Tecnologias móveis}

Pode-se definir "TI" como o conjunto de atividades e soluções advindas de recursos tecnológicos que visam à produção, ao armazenamento, à transmissão, ao acesso, à segurança e ao uso das informações. 
De outra forma, podemos dizer que a tecnologia é usada para o tratamento das informações, auxiliando o utilizador a alcançar determinado objetivo. A tecnologia pode ser encarada como uma resposta aos problemas cotidianos. Assim, não podemos limitar o seu campo de aplicação aos aparelhos inteligentes da atualidade, pois eles são recentes em nosso mundo e a tecnologia aparece muito antes do seu surgimento (Penedo, 2015).

A internete a telefonia móvel têm alcançado um expressivo crescimento nos últimos anos, tanto no Brasil, quanto em outros países. Em relação aos países com mais internautas do mundo, o Brasil assumiu em 2014 o quarto lugar no ranking, com quase 108 milhões de três bilhões de usuários que tem o mundo. A internet, associada aos artefatos computacionais portáveis, como notebook, palmtop, smartphone e tablete, possibilita níveis de conectividade nunca antes experimentados, o que vem despertando interesse nos meios acadêmico e empresarial (Lunardi; Dolci \& Wendland, 2013). Fruto desse avanço tecnológico, emergiu a expressão "Tecnologia da Informação móvel", que se tornou mais frequente a partir da terceira geração de celulares disponibilizada no Brasil em 2007, de onde surgiram os celulares inteligentes (smartphones) (Chaves et al, 2010).

Saccol e Reinhard (2007) mostram que a tecnologia móvel se caracteriza pela portabilidade, pela capacidade de se levar um dispositivo para qualquer lugar. Já a tecnologia sem fio (wireless) distingue-se pela possibilidade de o usuário se conectar a outros equipamentos por links de comunicação sem o uso de fio. Da fusão dessas duas tecnologias, têm-se as tecnologias móveis e sem fio (Tims) (Corso; Cavedon \& Freitas, 2011)

\section{Redes sociais e aplicativos mobile}

As redes sociais são definidas como uma estrutura sem fronteiras (Rangel \& Miranda, 2016), uma comunidade não geográfica que passa a representar um conjunto de participantes autônomos, unindo valores e interesses compartilhados (Marteleto, 2001). As redes sociais surgem em um ambiente pouco formal, onde a maioria das interações são motivadas por excitação e prazer (Ferreira et al, 2015). No entanto, mesmo surgindo numa esfera informal das relações sociais, os efeitos das redes podem ser percebidos fora de seus espaços, como por exemplo, na interação com o Estado, a sociedade e outras instituições representativas. Pequenas decisões passam a ser influenciadas pelo "macro", tendo a rede como intermediária (Marteleto, 2001).

As redes sociais possibilitaram às pessoas manifestar os seus pensamentos sobre assuntos diversos, criar conteúdos sobre tendências, fazer pedidos e reclamações e expressar anseios e angústias publicamente (Fernades et al, 2014), o que gera uma vasta gama de conteúdo online. De fato, a quantidade de informações geradas e compartilhadas é enorme, o que só vem aumentando ao longo do tempo. Segundo a Chaos IDC Digital (2014), só no ano de 2011, 1,8 zettabytes (ZB) de informações foram criadas e compartilhadas. O número mais que dobra a cada dois anos, sendo que, em 2013, foram 4,4 zettabytes e a previsão para 2020 é que sejam 44 zettabytes. O uso tão intenso da internet tem mudado a forma como interagimos e fazermos várias coisas no nosso, cotidiano possibilitando o surgimento de inúmeras ferramentas.

Os smartphones vêm se popularizando desde 2007 e angariando cada vez mais usuários no mundo. Segundo Turban et al (2010), diversos fatores impulsionam a rápida expansão da utilização de dispositivos móveis para acesso à internet, dentre eles estão: (a) a disseminação - o número de celulares cresce exponencialmente em todo o mundo; (b) a popularização - o uso de celular é um fenômeno social, principalmente na faixa etária de 15 a 25 anos; (c) o barateamento - o preço dos dispositivos móveis está mais acessível à população; (d) a funcionalidade - a introdução de novos recursos nos dispositivos os torna mais úteis no cotidiano; (e) a velocidade de transmissão de dados - a largura da banda hoje proporciona realizar operações que antes só eram possíveis usando computadores conectados à internet. 
Atualmente, existem algumas plataformas de aplicativos para smartphones, como por exemplo a iOS, Android ou a Windows Mobile (Pressman \& Maxim, 2016), e em cada uma delas há milhões de softwares disponíveis. Em 2014, as duas plataformas que mais tinham aplicativos disponíveis eram a Android, que na Play Store contava com 1,43 milhão de aplicativos, e a $i O S$, que na App Store hospedava 1,21 milhão de aplicativos (Olhar Digital, 2014). Os aplicativos voltados para comunicação e socialização são os mais populares, como o Twitter, Facebook, Linkedin e o Whatsapp. Eles constituem uma plataforma de comunicação para estabelecer, fortalecer e acelerar as relações sociais (Fernandes et al, 2014).

\section{TI na educação}

Atualmente, os dispositivos móveis afetam quase todas as áreas, do setor bancário até a política. À medida que os dispositivos ganham mais destaque em nível global, cresce a expectativa em torno da aprendizagem móvel. Alunos e professores já utilizam as tecnologias móveis em diversos contextos, aplicando-as a uma grande variedade de propósitos de ensino e aprendizagem (Shuler, Winters \& West, 2014).

Alguns historiadores afirmam que dispositivos, como por exemplo o computador de colo Dynabook (hoje conhecido como laptop), criado por Alan Kay em 1968, foram desenvolvidos para ajudar os alunos a aprender usando "novas mídias". Para subsidiar o projeto e a funcionalidade do dispositivo, Kay fundamentou-se nas teorias de renomados especialistas em aprendizagem (Dalakov, 2013). Segundo Shuler, Winters e West (2014), a educação e a tecnologia podem e devem evoluir lado a lado e servir de apoio uma à outra.

O design de hardware também é impulsionado pelas necessidades educacionais. Na Rússia, o tablet E-OK tem duas telas: uma para ler e outra para escrever. Essa configuração e a tecnologia em que se baseia foram desenvolvidas especificamente para acomodar tarefas educacionais (Silver, 2012). Muitos membros da comunidade de educação vêm trabalhando para que as mudanças tecnológicas impulsionem a pedagogia e para que a pedagogia influencie a tecnologia (Shuler, Winters \& West, 2014). As novas abordagens para a criação conversão de livros didáticos estão permitindo que eles deixem de ser meras reproduções digitais do conteúdo impresso para se tornar interfaces de grande riqueza visual, que podem incluir elementos multimídia, interativos e de colaboração (Gsma, 2011).

$\mathrm{Na}$ atual sociedade do conhecimento, o processo de ensino-aprendizagem passa por grandes transformações e todas as formas de escolas devem estar atentas a isso, uma vez que esses novos paradigmas estão definindo e delineando os modelos pedagógico-estruturais (Squirra \& Fedoce, 2011). Contudo, a aprendizagem móvel, em sua grande parte, tem se desenvolvido fora do ambiente formal da educação e a vasta maioria dos projetos de aprendizagem móvel foram pensados para contextos informais (Shuler, Winters \& West, 2014).

Com variados dispositivos presentes na vida dos alunos, auxiliando o processo de aprendizagem, tanto no ambiente formal e informal, surge o conceito de aprendizagem contínua ou seamless, que é uma forma de aprendizagem em que não há interrupções entre os diferentes ambientes. Nela, o discente usa vários tipos de tecnologia de acordo com as oportunidades que surgem, aproveitando o que cada uma tem de oferecer de melhor - a mobilidade de um smartphone, ou a superioridade do teclado de um computador, por exemplo. O objetivo é manter a continuidade da experiência de aprendizagem ao passar de um dispositivo ou ambiente ao outro. Ao longo da história, houve sempre uma grande divisão entre a aprendizagem formal, que ocorre dentro da sala de aula, e a informal, que acontece em casa ou em ambientes comunitários. Vários especialistas vêm investigando como a aprendizagem móvel pode ajudar a superar essa barreira e criar uma ponte entre a aprendizagem formal e a informal (Shuler; Winters \& West, 2014). 


\section{Tecnologias móveis e seus efeitos}

A internet tornou-se onipresente na vida moderna. De fato, estamos todos os dias expostos a milhares de dados e informações, a um infinito número de vídeos engraçados, a comunidades sociais, a trocas de mensagens instantâneas e a jogos, entre outros conteúdos. Com isso, têm surgido alguns transtornos mentais distintos ligados diretamente ao uso da tecnologia digital (Dashevsky, 2013). Segundo Bawden e Robinson (2009), a sobrecarga de informações em casos extremos pode trazer danos à saúde. Kirsh (2000) identifica uma condição de sobrecarga cognitiva, quando a sobrecarga de informação é adicionada a multitarefas e a interrupções.

Brabazon (2007) salienta que não só a sobrecarga de informações é um problema, mas também a baixa qualidade de alguns conteúdos à disposição de todos. A necessidade de manter-se conectado com familiares e amigos a qualquer tempo e lugar gera uma espécie de sentimento de obrigação com a tarefa de manter-se conectado, ou seja, acarreta um vício de ter o smartphone sempre ligado e constantemente atualizado (Mazmanian, Orlikowski \& Yates, 2006).

Evan Dashevsky (2013) listou alguns problemas trazidos ou reinventados pela era da banda larga móvel, dentre os quais cabe aqui destacar: (a) nomophobia - o termo é uma palavra-valise resultante da junção de "no-mobile" e "phobia", ou seja, trata-se do medo de ficar de telefone móvel, uma ansiedade que surge quando as pessoas ficam sem seu smartphone. Há relatos de uma sensação horrível por se estar desconectado quando, por exemplo, acaba a bateria do celular e não se tem onde carregá-lo; (b) depressão de Facebook - é a depressão causada por interações sociais ou pela falta delas no Facebook. Uma possível razão para isso, afirma a Evan Dashevsky (2013), está relacionada ao fato de que as pessoas tendem a documentar, nessa rede social, os aspectos mais fotogênicos de suas vidas: férias, promoções, fotos de festas, etc. Assim, cria-se a imagem (potencialmente equivocada) de que todos estão vivendo vidas muito mais felizes e bem-sucedidas do que o usuário que sofre deste problema; (c) transtorno de dependência da internet - trata-se de uma vontade constante e não saudável de acessar a internet; (d) vício de jogos online - relaciona-se a uma necessidade não saudável de acessar jogos multiplayer online; (e) hipocondria digital é a tendência de acreditar que você tem doenças sobre as quais leu online. Por exemplo, o usuário acorda um dia com dor de cabeça, que provavelmente não é nada sério, mas a WebMD (site americano voltado à saúde e ao bem-estar) diz que essas dores de cabeça são um dos sintomas de tumor no cérebro. Com isso, o sujeito passa a se considerar um doente terminal. Trata-se, em verdade, do raciocínio de um cibercondríaco, uma condição que conjuga informações médicas avulsas, chegando sempre aos piores cenários clínicos possíveis; (f) o efeito Google - que é a tendência do cérebro humano de reter menos informações porque ele sabe que as respostas estão ao alcance de alguns cliques.

De acordo com a literatura mencionada, foi elaborado o Quadro 1, que apresenta um resumo dos efeitos negativo das TI nas pessoas. Esses dados serviram de base para a elaboração dos instrumentos da pesquisa (apêndices A e B). 
Quadro 1 - Efeitos negativos da TI nas pessoas.

\begin{tabular}{|c|c|c|}
\hline $\begin{array}{c}\text { EFEITOS } \\
\text { NEGATIVOS }\end{array}$ & DESCRIÇÃO & FONTE \\
\hline Atenção parcial continua & $\begin{array}{l}\text { Um foco em ser conectado que resulta em estresse e déficit de atenção } \\
\text { característico. }\end{array}$ & Bawden e \\
\hline Distração e impaciência & $\begin{array}{l}\text { Devido ao excesso de estímulo mental, as pessoas ficam distraídas e } \\
\text { impacientes. }\end{array}$ & $\begin{array}{l}\text { Robinson } \\
(2009)\end{array}$ \\
\hline Sobrecarga de dados & $\begin{array}{l}\text { A TI móvel disponibiliza informações de todos os tipos em qualquer } \\
\text { momento e lugar, dificultando saber qual informação é útil. }\end{array}$ & \\
\hline Interrupções desnecessárias & 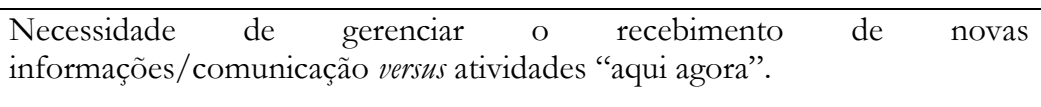 & Saccol (2005) \\
\hline Isolamento e individualismo & $\begin{array}{l}\text { As pessoas realizam quase tudo de que precisam por meio da TI, eliminando } \\
\text { a necessidade de contato direto com outras pessoas. }\end{array}$ & \\
\hline Caos & $\begin{array}{l}\text { A tecnologia muitas vezes é usada para organizar e controlar grupos de } \\
\text { pessoas. Por outro lado, pode gerar desordem e descontrole. }\end{array}$ & \multirow{4}{*}{$\begin{array}{c}\text { Mick e Founier } \\
\text { (1998) e } \\
\text { Javenpaa e } \\
\text { Lang (2005) }\end{array}$} \\
\hline Escravidão & $\begin{array}{l}\text { O usuário torna-se dependente da tecnologia, não se vê fazendo suas } \\
\text { atividades fora dela, o que gera uma espécie de escravidão. }\end{array}$ & \\
\hline Ineficiência & $\begin{array}{l}\text { No caso de não saber usar a tecnologia, ela fará com que o usuário seja menos } \\
\text { produtivo no trabalho ou nos estudos. }\end{array}$ & \\
\hline Criação de necessidades & $\begin{array}{l}\text { A tecnologia cria a necessidade de novas tecnologias; assim, quanto mais } \\
\text { tecnologia se tem, mais tecnologia se quer. }\end{array}$ & \\
\hline Nomophobia & O termo é uma junção "no-mobile" e "phobia" - medo de ficar sem celular. & \multirow{2}{*}{$\begin{array}{l}\text { Dashevsky } \\
\text { (2013) }\end{array}$} \\
\hline Depressão de Facebook & $\begin{array}{l}\text { É a depressão causada por interações sociais, ou a falta de interações sociais } \\
\text { no Facebook. }\end{array}$ & \\
\hline $\begin{array}{l}\text { Transtorno de dependência } \\
\text { da internet }\end{array}$ & Uma vontade constante e não saudável de acessar a internet. & \multirow{2}{*}{$\begin{array}{l}\text { Dashevsky } \\
\text { (2013) }\end{array}$} \\
\hline Hipocondria digital & É a tendência de acreditar que você tem doenças sobre as quais leu online. & \\
\hline Efeito Google & $\begin{array}{l}\text { É a tendência do cérebro humano de reter menos informação porque ele } \\
\text { sabe que as respostas estão ao alcance de alguns cliques. }\end{array}$ & $\begin{array}{c}\text { Sparrow; Liu e } \\
\text { Wegner (2011) } \\
\text { e Dashevsky } \\
\text { (2013) }\end{array}$ \\
\hline
\end{tabular}

Fonte: Elaborado pelos autores, adaptado da literatura.

\section{Método}

Quanto à natureza, este artigo se enquadra como uma pesquisa aplicada, pois visa a gerar conhecimentos dirigidos à solução de problemas específicos, envolvendo verdades e interesses locais (Silva \& Menezes, 2005). Adotou-se uma abordagem qualitativa, que envolve compreensão de um evento em seu ambiente natural, com trabalho de campo que resulta em um produto descritivo (Merriam, 1998). Quanto ao método de raciocínio, foi usado o dedutivo, pois os dados analisados permitiram inferir uma verdade (Gil, 2008).

A pesquisa é também exploratória, pois visa proporcionar familiaridade com o seguinte problema: o uso de TI pelos discentes na percepção dos docentes e dos próprios usuários. Conforme nota Gil (2010), 
uma pesquisa exploratória, na maioria dos casos, contempla: (a) levantamento bibliográfico; (b) entrevista com pessoas que tiveram experiências práticas com o problema pesquisado; e (c) análise de exemplos que "estimulem a compreensão". Levando em conta essas informações, os objetivos desta pesquisa e a proximidade com o grupo pesquisado, a coleta de dados foi realizada por meio de múltiplas fontes, com gravações de áudios e anotações pertinentes.

\section{Coleta de dados}

Como fonte de coleta de dados, além da observação direta, optou-se pela entrevista semiestruturada com os docentes e com grupo focal de discentes. Isso permitiu analisar os diferentes pontos de vista em relação ao tema abordado. $\mathrm{Na}$ entrevista semiestruturada com os docentes, foram entrevistados nove professores da Universidade Federal de Rondônia (Unir), campus de Vilhena, sendo quatro do curso de Administração e cinco do curso de Ciências Contábeis, por acessibilidade e aceite. Foi usada uma lista de questões e de tópicos para serem respondidos, que serviram de guia (Apêndice B). As entrevistas tiveram duração média de 20 minutos de gravação. Os áudios resultantes foram transcritos e analisados. Optouse por flexibilizar as entrevistas; as questões não seguiram precisamente a ordem prevista no guia e novas perguntas puderam ser formuladas no decorrer da conversa (Mattos, 2005). De forma geral, contudo, a entrevista observou o roteiro.

Segundo Marconi e Lakatos (2010), a entrevista semiestruturada permite ao entrevistador seguir um roteiro previamente estabelecido, tendo, porém, o entrevistador a liberdade de direcionar o diálogo em qualquer direção. Essa flexibilidade também permite ao entrevistado esclarecer perguntas de forma a garantir a sua compreensão. As principais vantagens das entrevistas semiestruturadas são as seguintes: possibilidade de acesso a mais informações além das previstas; possibilidade de esclarecer aspectos da entrevista; acesso a diferentes pontos de vista, orientações e hipóteses para o aprofundamento da investigação; e definição de novas estratégias e de outros instrumentos (Tomar, 2007).

Como segunda fonte de coleta de dados, foi utilizado o grupo focal com os discentes do curso de Administração e de Ciências Contábeis da Unir. Foram entrevistados oito alunos de quatro turmas diferentes, com idades entre 21 e 31 anos. O grupo focal aconteceu em uma sala do campus no mês de junho de 2017, rendendo duas horas de gravação que foram transcritas e analisadas. A essência do grupo focal consiste justamente na interação entre os participantes e o pesquisador, que obtém dados a partir da discussão focada em tópicos específicos e diretivos.

A coleta de dados por meio do grupo focal tem como uma de suas maiores riquezas o fato de que se baseia na inclinação humana de formar opiniões e atitudes a partir da interação com outros indivíduos (Iervolino \& Pelicioni, 2001). O grupo focal com discentes, conduzido por outro discente (o próprio pesquisador), em ambiente reservado, sem a presença de outros atores da universidade (professores, técnicos etc.), possibilitou, entende-se, uma maior abertura e transparência por parte dos alunos nas informações fornecidas, facilitando a extração de dados da pesquisa e permitindo uma maior compreensão do fenômeno.

\section{Método de análise de dados}

Os dados obtidos por meio das entrevistas e do grupo focal são objeto da análise de conteúdo neste estudo que, segundo Martins e Theóphilo (2009), busca apreender a essência de um texto nos detalhes das informações, dados e evidências disponíveis. Assim, o método não trabalha somente com o texto per se, mas também com detalhes do contexto. Será utilizada a análise de conteúdo, adotando as categorias de análise definidas a priori, como consta no Quadro 1 já apresentado. Para Bardin (2011), a análise de conteúdo, enquanto método, é um conjunto de técnicas de análise das comunicações, que utiliza procedimentos sistemáticos e objetivos de descrição do conteúdo das mensagens. 


\section{Resultados}

Esta seção aborda os dados coletados nas entrevistas com docente e com grupo focal e também durante a observação direta. Adicionalmente, é apresentada uma discussão sobre os achados da pesquisa.

\section{Caracterização dos participantes}

Os participantes das entrevistas integram o corpo docente da Unir, campus de Vilhena, sendo quatro do curso de Ciências Contábeis e cinco do curso de Administração. As entrevistas foram realizadas na própria universidade, individualmente. A fim de manter sigilo quanto à identificação individual dos docentes, seus nomes foram substituídos por números de 1 a 10 - por exemplo, "professor 6". Foram nove entrevistados (Obs.: um professor foi citado durante o grupo focal e adicionado aos nove docentes entrevistados). O grupo focal, por sua vez, foi constituído por discentes da Unir, alunos de Ciências Contábeis e Administração. Foram entrevistados dois discentes de cada turma, das duas turmas mais próximas da conclusão de cada curso, somando oito discentes no total, quatro do sexo masculino e quatro do sexo feminino, com idades entre 21 e 31 anos (definidos voluntariamente entre os pares). Quanto à identificação desses participantes, os seus nomes foram substituídos por letras de $\mathrm{A}$ a $\mathrm{H}$ - por exemplo, "participante C". O grupo focal aconteceu em uma sala da universidade no mês de junho de 2017 e foi conduzido por outro discente, em ambiente reservado, sem a presença de outros atores da universidade (e.g. professores, técnicos etc.). Foi mantido total sigilo da identificação dos participantes, o que, presume-se, possibilitou maior abertura e transparência das informações, facilitando a obtenção de dados e uma maior compreensão do fenômeno.

\section{Uso de TI móvel em sala de aula: perspectiva discente}

Quando perguntados sobre qual seria a motivação para o uso de TI móvel em sala de aula, a maioria dos alunos responderam que, quando não conseguem prestar atenção à aula, eles dedicam atenção ao smartphone. Foi o que disse o participante C: "tem dias que realmente eu deixo só para mexer porque a aula está muito chata, aí eu fico só ali mexendo, mas eu acho que não me atrapalha não". Outros motivos, como costume, necessidade e curiosidade para saber de algo que está acontecendo fora da sala, foram citados. Por outro lado, o participante A afirmou que só utiliza o celular para fins relacionados à aula quando necessário. O participante $G$ utiliza o seu aparelho para conferir se o que está sendo apresentado pelo professor está de acordo com o que ele pode encontrar na internet.

Outro questionamento feito foi em relação aos efeitos negativos do uso da TI móvel em sala de aula no trabalho docente. A pergunta foi: como imaginam que os docentes se sentem quando os discentes estão utilizando TI móvel dentro de sala de aula? Isso impacta diretamente o trabalho dos docentes? Os discentes, em sua maioria, afirmam que se colocam no lugar dos professores e dizem que se sentiriam desmotivados, como afirma a participante C: "Eu acho que impacta negativamente, e o principal fator é a desmotivação". O participante $\mathrm{E}$ também afirma: "Eu acho que é negativo, com certeza. É uma falta de educação até, às vezes acontece involuntariamente, né?, a gente acaba pegando [o celular] um minutinho".

Foi também questionado qual seria o sentimento dominante dos discentes quando utilizam TI móvel dentro de sala de aula. As respostas ficaram bem divididas. Alguns relatam que não se sentem confortáveis utilizando a internet na sala de aula. É o caso da participante A: "Eu me sinto desconfortável". Alguns afirmaram que se trata de falta de educação, como o participante G: "Eu acho, assim, que é uma falta de respeito com o professor que está ali dando aula". Um outro grupo de entrevistados, por outro lado, dizem que se trata de uma coisa normal. Essa é a opinião da participante B: "Eu vou dizer tranquila, porque eu já acho que é uma coisa normal”. Segundo esse grupo de alunos, se os professores se sentem mal, não deveriam. O participante E argumenta do seguinte modo: "Acho que ele não deveria se sentir mal, com aquilo, né?, a menos que a sala inteira esteja mexendo no celular". 


\section{Uso de TI móvel em sala de aula: a perspectiva docente}

Em relação à motivação para o uso de TI móvel, a maioria dos professores afirmaram que não solicitam a utilização de equipamentos pessoais de TI móvel durante as aulas. Assim, eles acreditam que o aspecto motivador do uso desses equipamentos sejam fins alheios aos propósitos da aula. Os professores relatam que, para que possam solicitar o uso TI móvel em sala de aula, é necessário que pelo menos a maioria tenha acesso a um aparelho de TI móvel e à internet. O professor 10 afirmou: "Eu dificilmente solicito que eles consultem na aula. Por que eu não faço esse tipo de trabalho com essas TIs? Porque requer acesso à internet". O professor 4 acrescenta: "Eu acho que a fonte deles não é a pesquisa do conteúdo em si. Eu acho que é mais essas redes sociais mesmo, dar uma escapada, fugir um pouco do foco da aula e dar uma olhadinha lá".

Quando indagados sobre a sensação ou o sentimento diante do uso de TI móvel durante as aulas, a maioria dos professores participantes da pesquisa afirmaram que não se sentem muito incomodados com tal prática, pois dizem que são poucos discentes que realmente utilizam seus equipamentos para outros fins que não os relacionados à aula. O professor 6 afirmou: "Eu não ligo tanto se ele está usando o smartphone ou não. 99,9\% das vezes quando eu vejo isso eu brinco e aí eu peço para o aluno parar". Por outro lado, alguns professores disseram que se sentem, sim, incomodados; outros afirmaram que se sentem desmotivados e/ou irritados. É o caso do professor 8: "A TI usada para as redes sociais durante uma aula expositiva, isso desagrada sim, mas isso é muito pontual, nunca é uma sala inteira fazendo isso". O professor 7, por sua vez, afirmou: "Confesso que me irrita às vezes perceber que o aluno está distraído por causa do uso das redes sociais, do Facebook, Whatsapp ou qualquer outra que seja".

\section{Efeitos negativos da TI móvel e discussão}

No Quadro 2, é apresentado o resumo das percepções dos docentes em relação aos efeitos aos quais os discentes estão expostos quando utilizam TI móvel em sala de aula. São também apresentadas, no mesmo quadro, as percepções dos discentes em relação aos efeitos sentidos no dia a dia com o uso da tecnologia.

Os resultados da pesquisa corroboraram os resultados de Bawden e Robinson (2009), Saccol (2005), Mick e Founier (1998), Javenpaa e Lang (2005) e Dashevsky (2013). Pode-se notar que os efeitos negativos apresentados por esses autores são percebidos no dia a dia acadêmico por docentes e discentes da universidade pesquisada. Esses efeitos negativos podem constituir um óbice para a aprendizagem contínua, citada por Shuler, Winters e West (2014). Os autores afirmam que, por um lado, as tecnologias móveis à disposição dos discentes também oferecem condições de aprendizagem contínua, criando uma ponte entre o ensino formal (dentro da sala de aula) e informal (fora da sala de aula). A tecnologia usada para disseminar conhecimento, incrementando a produção acadêmica, é uma realidade (Souza et al, 2016).

Segundo Shuler, Winters e West (2014), a educação e a tecnologia podem e devem evoluir lado a lado para servir de apoio uma à outra. Por outro lado, é necessário destacar que o desenvolvimento de iniciativas de aprendizagem móvel demanda tempo e empenho de docentes e de instituições de ensino. Projetar novos métodos de aprendizagem, assim como possibilitar que os alunos compreendam os potenciais das mídias móveis (Squirra \& Fedoce, 2011), leva tempo. Nesse sentido, conhecer os efeitos negativos da tecnologia na realidade das instituições de ensino colabora para o desenvolvimento de iniciativas de aprendizagem contínua mais efetivas ligadas aos dispositivos de TI móvel.

Em análise geral constata-se que os efeitos negativos apresentados poderiam ser reduzidos se a utilização das TI forem implementadas como estratégias de ensino e aprendizagem por parte das instituições de ensino superior, como por exemplo a grande quantidade de informações disponíveis na rede mundial de computadores dificulta saber o que é uma informação verídica e que pode ser utilizada pelo discente em sua vida acadêmica. Porém, para o docente que, em regra, tem experiência e tempo de estudo, é mais fácil distinguir a informação falsa da verdadeira, podendo assim orientar discentes sobre onde pesquisar e como pesquisar com vistas a facilitar o processo de aprendizado. 
Quadro 2 - Efeitos negativos do uso da TI móvel na sala de aula segundo por docentes e discentes.

\begin{tabular}{|c|c|c|c|}
\hline $\begin{array}{l}\text { Efeitos } \\
\text { negativos } \\
\text { (TI móvel } \\
\text { em sala) }\end{array}$ & Literatura & Perspectiva docente & Perspectiva discente \\
\hline $\begin{array}{l}\text { Atenção } \\
\text { parcial } \\
\text { contínua }\end{array}$ & $\begin{array}{l}\text { Foco em estar conectado que } \\
\text { resulta em estresse e déficit de } \\
\text { atenção característico (Bawden \& } \\
\text { Robinson, 2009). }\end{array}$ & $\begin{array}{l}\text { Alguns discentes têm a atenção } \\
\text { dividida entre suas TIs móveis e a } \\
\text { aula. }\end{array}$ & $\begin{array}{l}\text { A atenção dividida com a TI } \\
\text { móvel é considerada normal; } \\
\text { trata-se de um costume } \\
\text { advindo da utilização diária. }\end{array}$ \\
\hline $\begin{array}{l}\text { Distração e } \\
\text { impaciência }\end{array}$ & $\begin{array}{l}\text { Devido ao excesso de estímulo } \\
\text { mental, as pessoas ficam } \\
\text { distraídas e impacientes (Bawden } \\
\text { \& Robinson, 2009). }\end{array}$ & $\begin{array}{l}\text { Pelo excesso de estímulo metal no } \\
\text { dia a dia, os discentes gostariam de } \\
\text { uma aula mais ligada à TI móvel. }\end{array}$ & $\begin{array}{l}\text { Sempre que possível, os } \\
\text { discentes utilizam mais de uma } \\
\text { TI ao mesmo tempo. O } \\
\text { excesso de estímulo mental } \\
\text { causa distração e impaciência. }\end{array}$ \\
\hline $\begin{array}{l}\text { Sobrecarga de } \\
\text { dados }\end{array}$ & $\begin{array}{l}\text { A TI móvel disponibiliza } \\
\text { informações de todos os tipos em } \\
\text { qualquer momento e lugar. É } \\
\text { difícil saber qual informação é útil } \\
\text { (Saccol, 2005). }\end{array}$ & $\begin{array}{l}\text { Os discentes têm dificuldades em } \\
\text { filtrar informações fidedignas a } \\
\text { partir do oceano de informações } \\
\text { disponíveis na rede. }\end{array}$ & $\begin{array}{l}\text { A maioria dos discentes tem } \\
\text { dificuldades de filtrar as } \\
\text { informações obtidas pela } \\
\text { móvel. }\end{array}$ \\
\hline $\begin{array}{l}\text { Interrupcões } \\
\text { desnecessárias }\end{array}$ & $\begin{array}{l}\text { Necessidade de gerenciar o } \\
\text { recebimento de novas } \\
\text { informações/comunicação versus } \\
\text { atividades "aqui agora" (Saccol, } \\
\text { 2005). }\end{array}$ & $\begin{array}{l}\text { Um ou outro discente acaba saindo } \\
\text { da sala para atender o telefone ou até } \\
\text { mesmo responder e-mails ou } \\
\text { mensagens. }\end{array}$ & $\begin{array}{l}\text { As interrupções acontecem } \\
\text { mais discretamente nas trocas } \\
\text { de mensagens online. }\end{array}$ \\
\hline $\begin{array}{l}\text { Isolamento e } \\
\text { individualismo }\end{array}$ & $\begin{array}{l}\text { As pessoas realizam quase tudo de } \\
\text { que precisam por meio da TI, } \\
\text { eliminando a necessidade de } \\
\text { contato direto com outras pessoas } \\
\text { (Saccol, 2005). }\end{array}$ & $\begin{array}{l}\text { Os discentes buscam esclarecer } \\
\text { dúvidas sobre o conteúdo da aula na } \\
\text { TI móvel. }\end{array}$ & $\begin{array}{l}\text { A busca independente pelo } \\
\text { conteúdo diminui o contato } \\
\text { direto do discente com o } \\
\text { docente. }\end{array}$ \\
\hline Caos & $\begin{array}{l}\text { A tecnologia muitas vezes é usada } \\
\text { para organizar e controlar grupos } \\
\text { de pessoas. Por outro lado, pode } \\
\text { gerar desordem e descontrole } \\
\text { (Mick \& Founier, 1998). }\end{array}$ & $\begin{array}{l}\text { Baixa ocorrência em sala de aula. } \\
\text { Alguns docentes fazem um acordo } \\
\text { prévio para a utilização dos } \\
\text { equipamentos de TI a fim } \\
\text { reduzir/eliminar esse efeito } \\
\text { negativo. }\end{array}$ & $\begin{array}{l}\text { Baixa ocorrência. Contudo, } \\
\text { alguns alunos citam que } \\
\text { quando a tecnologia é usada } \\
\text { para discutir política ou } \\
\text { religião, as chances de causar o } \\
\text { caos são grandes. }\end{array}$ \\
\hline Escravidão & $\begin{array}{l}\text { O usuário torna-se dependente da } \\
\text { tecnologia, não se vê fazendo suas } \\
\text { atividades fora dela, o que gera } \\
\text { uma espécie de escravidão (Mick } \\
\text { \& Founier, 1998). }\end{array}$ & $\begin{array}{l}\text { Relatam que os discentes estão } \\
\text { acostumados a utilizar a TI móvel } \\
\text { para realizar as mais diversas } \\
\text { atividades e, portanto, não ficariam } \\
\text { sem seus equipamentos. }\end{array}$ & $\begin{array}{l}\text { Quanto mais coisas puderem } \\
\text { ser feitas pela TI móvel melhor. }\end{array}$ \\
\hline
\end{tabular}


Quadro 2 - Efeitos negativos do uso da TI móvel na sala de aula segundo por docentes e discentes (continuação).

\begin{tabular}{|c|c|c|c|}
\hline $\begin{array}{l}\text { Efeitos } \\
\text { negativos } \\
\text { (TI móvel } \\
\text { em sala) }\end{array}$ & Literatura & Perspectiva docente & Perspectiva discente \\
\hline Ineficiência & $\begin{array}{l}\text { No caso de não saber usar a } \\
\text { tecnologia, ela fará com que o } \\
\text { usuário seja menos produtivo no } \\
\text { trabalho ou nos estudos } \\
\text { (Javenpaa \& Lang, 2005). }\end{array}$ & $\begin{array}{l}\text { Causada porque os discentes não } \\
\text { dominam plataformas online que } \\
\text { são úteis no meio acadêmico. }\end{array}$ & $\begin{array}{l}\text { Baixa ocorrência, pois } \\
\text { acreditam que podem } \\
\text { aprender a dominar qualquer } \\
\text { TI móvel com facilidade. }\end{array}$ \\
\hline $\begin{array}{l}\text { Criação de } \\
\text { necessidades }\end{array}$ & $\begin{array}{l}\text { A tecnologia cria a necessidade } \\
\text { de novas tecnologias; assim, } \\
\text { quanto mais tecnologia se tem, } \\
\text { mais tecnologia se quer } \\
\text { (Javenpaa \& Lang, 2005). }\end{array}$ & $\begin{array}{l}\text { Os docentes percebem que há uma } \\
\text { busca, entre os discentes, pelo } \\
\text { melhor equipamento de TI. }\end{array}$ & $\begin{array}{l}\text { Sempre que possível querem } \\
\text { ter mais tecnologia. }\end{array}$ \\
\hline Nomophobia & $\begin{array}{l}\text { O termo é uma junção "no- } \\
\text { mobile" e "phobia" - medo de } \\
\text { ficar sem celular (Dashevsky, } \\
\text { 2013). }\end{array}$ & $\begin{array}{l}\text { Baixa ocorrência em sala de aula; } \\
\text { acreditam que os discentes não têm } \\
\text { esse medo. }\end{array}$ & $\begin{array}{l}\text { Têm medo de ficar sem a TI } \\
\text { móvel, pois é o principal meio } \\
\text { de comunicação de que } \\
\text { dispõem. }\end{array}$ \\
\hline $\begin{array}{l}\text { Depressão } \\
\text { de Facebook }\end{array}$ & $\begin{array}{l}\text { É a depressão causada por } \\
\text { interações sociais, ou a falta de } \\
\text { interações sociais no Facebook } \\
\text { (Dashevsky, 2013). }\end{array}$ & $\begin{array}{l}\text { Não sustentado. Os docentes não } \\
\text { percebem essa depressão nos } \\
\text { discentes. }\end{array}$ & $\begin{array}{l}\text { Não sustentado. } r \text { Mesmo } \\
\text { dizendo ser possível que } \\
\text { aconteça, } \\
\text { entrevistado diz ter sentido } \\
\text { esse efeito. }\end{array}$ \\
\hline $\begin{array}{l}\text { Transtorno } \\
\text { de } \\
\text { dependência } \\
\text { da internet }\end{array}$ & $\begin{array}{l}\text { Uma vontade constante e não } \\
\text { saudável de acessar à internet } \\
\text { (Dashevsky, 2013). }\end{array}$ & $\begin{array}{l}\text { Os docentes relatam que os } \\
\text { discentes, vez ou outra, estão } \\
\text { olhando os seus smartphones em } \\
\text { busca do acesso à internet. }\end{array}$ & $\begin{array}{l}\text { Sempre estão verificando o } \\
\text { recebimento de novas } \\
\text { informações advindas da } \\
\text { internet. }\end{array}$ \\
\hline $\begin{array}{l}\text { Hipocondria } \\
\text { digital }\end{array}$ & $\begin{array}{l}\text { É a tendência de acreditar que } \\
\text { você tem doenças sobre as quais } \\
\text { leu on-line (Dashevsky, 2013). }\end{array}$ & $\begin{array}{l}\text { Baixa ocorrência em sala de aula, } \\
\text { os docentes relatam ser um } \\
\text { costume da sociedade que reflete } \\
\text { em sala. }\end{array}$ & $\begin{array}{l}\text { Realizam pesquisas on-line } \\
\text { acerca dos sintomas de } \\
\text { doenças. }\end{array}$ \\
\hline $\begin{array}{l}\text { Efeito } \\
\text { Google }\end{array}$ & $\begin{array}{l}\text { É a tendência do cérebro humano } \\
\text { de reter menos informação } \\
\text { porque ele sabe que as respostas } \\
\text { estão ao alcance de alguns } \\
\text { cliques (Sparrow, Liu \& } \\
\text { Wegner, 2011). }\end{array}$ & $\begin{array}{l}\text { A facilidade com que se acha } \\
\text { informações sobre os assuntos } \\
\text { abordados em sala faz com que os } \\
\text { discentes guardem menos conteúdo } \\
\text { na memória. }\end{array}$ & $\begin{array}{l}\text { Dizem ser um costume; } \\
\text { quando vão falar ou escrever } \\
\text { sobre um assunto buscam } \\
\text { primeiro no Google. }\end{array}$ \\
\hline
\end{tabular}


Do Quadro 2, onde se comparam os efeitos encontrados na literatura com as percepções de docentes e discentes, vale destacar três efeitos dos quais os docentes divergem em relação aos discentes. Sobre o efeito ineficiência, os discentes alegam que dominam a tecnologia e qualquer ineficiência causada pela TI é passageira; já os docentes percebem que os discentes têm dificuldade em dominar plataformas úteis e utilizá-las em benefício dos estudos. Em relação ao efeito nomophobia, os discentes relatam ter medo de perder o aparelho móvel, pois se trata do principal meio de comunicação que possuem com colegas de sala, familiares e colegas de trabalho, entre outros. O smartphone é responsável também por armazenar conteúdos importantes da universidade e do trabalho. Porém, esse medo não é percebido pelos docentes. Sobre a depressão Facebook, os achados da pesquisa divergem dos resultados relatados por Dashevsky (2013). De fato, esse efeito negativo não foi percebido pelos docentes e discentes. Os participantes relatam que há a possibilidade de que ocorra tal efeito na universidade, mas nunca passaram por isso. Trata-se, portanto, do único efeito que, segundo docentes e discentes, não ocorre na sala de aula.

É importante destacar que o efeito Google foi o mais comentado pelos participantes da pesquisa. Docentes e discentes sentem que o efeito acontece na sala de aula, corroborando com os achados de Sparrow, Liu e Wegner (2011). Isso demanda do docente uma estratégia para lecionar a aula de forma a que o discente retenha o máximo de conteúdo. Sparrow, Liu e Wegner (2011) demonstram em sua pesquisa que quando as pessoas esperam que a informação fique continuamente disponível é mais provável que se lembrem de onde encontrá-la do que da informação em si. Isso torna os usuários mais dependentes de aparelhos. Desse modo, deve-se permanecer conectado para se saber o que o Google 'sabe'. Assim, a experiência de perder a conexão com a internet se torna cada vez mais algo como perder um amigo (Sparrow, Liu \& Wegner, 2011).

Observa-se que os discentes mudaram sua forma de aprender e interagir em sala de aula, e um fator que colaborou para essa mudança é a contínua utilização do smartphone pelos discentes, o que lhes possibilitou uma nova percepção do mundo. Nesse sentido a utilização do smartphone em sala de aula como ferramenta de aprendizagem incentivada por professores e coordenadores poderia ser útil para um modelo de ensino alinhado com a forma de aprendizagem dos discentes. Forma essa que já utilizam no dia a dia, para pesquisarem e aprenderem sobre diversos outros assuntos que lhes despertam o interesse. O conhecimento de sala de aula poderia ser passado por vídeo aula, aplicativos que incentivam o estudo (como por exemplo o aplicativo Duolingo, utilizado para aprender línguas estrangeiras), entrega de trabalho em formato digital, cursos extracurriculares voltados a ensinar os discentes como utilizar a TI ao favor dos estudos em sala de aula, entre outros.

\section{Considerações finais}

O ensino e a aprendizagem do futuro ocorrerão em um mundo muito mais conectado, com tecnologia mais barata e acessível (Shuler; Winters \& West, 2014). As tecnologias que promovem mais eficiência e praticidade no dia a dia também podem ter os seus efeitos negativos (Mick \& Founier, 1998; Javenpaa \& Lang, 2005; Saccol, 2005; Bawden \& Robinson, 2009; Dashevsky, 2013). Com o crescente uso das tecnologias na educação, efeitos negativos do uso de TI móvel foram evidenciados na literatura e reunidos na seção do referencial teórico. Esta pesquisa procurou verificar se alguns desses efeitos negativos (Quadro 1) se manifestam nas salas de aula de uma Universidade Federal.

A revisão da literatura listou 14 efeitos negativos da TI nas pessoas (Quadro 1). Dessa lista, 13 efeitos foram identificados pelos docentes e discentes participantes. $O$ único efeito não percebido foi o efeito depressão Facebook.

Os resultados evidenciam também que os discentes procuram realizar as tarefas escolares em seus equipamentos de TI móvel. Por exemplo, tiram fotos do quadro em vez de copiar no caderno, 
usam livros em formato PDF, em vez de adquirirem livros físicos, entre outras. Os discentes retêm menos conteúdo na memória, não se aprofundam nos conteúdos passados pelos professores e preocupam-se mais com como achar o que foi ensinado. Assim, sabem em que fonte buscar para responder a um futuro questionamento, mas têm poucos argumentos acerca de assuntos variados.

Este artigo lança uma contribuição para a área de sistemas da informação e para universidades, docentes e discentes, questionando aspectos da utilização de TI móvel. Parte-se aqui do princípio de que, sabendo destes efeitos, podem ser criadas políticas para redução desses impactos em sala de aula, promovendo um ambiente de ensino mais eficiente.

As potenciais contribuições do estudo envolvem múltiplos agentes. A partir dos resultados pretende-se contribuir com informações às instituições de ensino para melhor compreensão do fenômeno do uso de TI móvel e seus efeitos negativos. Gestores e docentes poderão planejar melhor a utilização de TI dentro do espaço universitário, tornando os recursos tecnológicos mais eficientes quando da sua utilização em prol do ensino-aprendizado.

Para a comunidade científica o estudo demonstra que ainda há reduzido número de pesquisas sobre os efeitos negativos da TI móvel no ambiente analisado, evidenciando a possibilidade de análises mais profundas sobre temas relacionados nos estudos futuros. A busca por entender os efeitos negativos que seguem uso de TI móvel é tão importante quanto usufruir dos seus efeitos positivos.

Para os discentes e docentes, os quais estão envolvidos diretamente com os efeitos negativos da TI móvel em sala de aula, o estudo busca apresentar uma visão imparcial de cada lado, onde o docente pode conhecer melhor seus discentes e suas opiniões sobre o uso de TI móvel em sala de aula e o discente pode entender melhor como o docente percebe a utilização desses equipamentos em sala de aula e suas dificuldades para implementação de novos modelos de ensino-aprendizagem.

A pesquisa se limitou ao estudo de caso nos cursos de Ciências Contábeis e Administração em uma Universidade Federal. Contudo, para inibir eventuais efeitos do estudo de caso único, foram adotadas estratégias como a investigação dos dois principais agentes envolvidos no uso da TI móvel (professores e discentes) e abordagens complementares para a identificação dos efeitos do uso da TI móvel (entrevista, grupo focal). Sugere-se que, para pesquisas futuras, outros cursos e universidades sejam pesquisados. Pode-se também investigar como a realidade aqui descrita se altera no tempo, ou seja, se os efeitos apresentados serão reduzidos ou aumentados, principalmente, diante das variações tecnológicas e tendências de uso da TI.

\section{Referências}

Bawden, D.; Robinson, L (2009). The dark side of information: overload, anxiety and other paradoxes and pathologies. Journal Information Science, v. 35, n. 2.

Bardin, L. (2011). Análise de conteúdo. São Paulo: Edições 70.

Bento, M. C. M; Cavalcante, R. S. (2013). Tecnologias móveis em educação: o uso do celular na sala de aula. Revista ECCOM, v. 4, n. 7, jan./jun. São Paulo

Brarabazon, T. (2007). The University of Google: Education in the Information Age. Ashgate, Aldershot, UK.

Cappellozza, A., Moraes, G. H. S. M., \& Muniz, L. M. (2017). Uso Pessoal das Tecnologias no Trabalho: Motivadores e Efeitos à Distração Profissional . Revista de Administração Contemporânea, 21(5), 605-626.

Chadha, R. (2014). Global Mobile Landscape. eMarketer, Nova York, 2014. Recuperado em 10 de outubro de 2016, de https://www.emarketer.com/. 
Chaves, S. et al (2010). Adoção da internet móvel para uso pessoal. Proceedings of the AMCIS. Recuperado em 10 de outubro de 2016, de http://aisel.aisnet.org/amcis2010/195.

Dalakov, G. (2013). The Dynabook of Alan Kay. History of Computers. Recuperado em 12 de outubro de 2016, de http://history-computer.com/ModernComputer/Personal/Dynabook.html.

Dashevsky, E. (2013). Oito novas doenças provocadas pelo uso da internet. Você tem alguma? IDGNOW. Recuperado em 15 de outubro de 2016, de http://idgnow.com.br/internet/2013/10/16/oito-novas-doencas-mentais-que-atingem-vocepor-causa-da-internet/.

Fernandes, R. F. et al (2014). A aquisição de conhecimento no processo de identificação de oportunidades nas redes sociais on-line. Perspectivas em Gestão \& Conhecimento, v. 4, n. esp., p. 109-132.

Ferreira, J. B. et al (2015). Tecnologias Interativas: Efeitos no Varejo de Vestuário Online. Revista Eletrônica de Estratégia \& Negócios, v. 8, n. 2, p. 241-265.

GIL, A. C. (2008). Como elaborar projetos de pesquisa. 5. ed. São Paulo: Atlas.

Métodos e técnicas de pesquisa social. 6. ed. São Paulo: Atlas.

GSMA (2011). Mobile education landscape report. London. Recuperado em 12 de outubro de 2016, de

http://www.gsma.com/connectedliving/wpcontent/uploads/2012/03/landscape110811interacti ve.pdf.

IDC (International Data Corporation) (2014). Recuperado em 15 de outubro de 2016, de http://www.emc.com/collateral/analyst-reports/idc-digital-universe-2014.pdf.

Iervolino, S. A.; Pelicioni, M. C. F. (2001). A utilização do grupo focal como metodologia qualitativa na promoção da saúde. Revista Escola Enfermagem - USP, São Paulo, v. 35, n. 2, p. 15-21.

Jarvenpaa, S.; Lang, K. (2005). Managing the paradoxes of mobile technology. Information Systems Management, v. 22, n. 4, p. 7-23.

Kirsh, D. (2000). A Few Thoughts on Cognitive Overload. Intellectica, v. 30, p. 19-51.

Lunardi, G. L.; Dolci, D. B.; Wendland, J. (2013). Internet Móvel nas organizações: fatores de adoção e impactos sobre o desempenho. Revista de Administração Contemporânea, v. 17, n. 6, p. 679703.

Marteleto, R. M. (2001). Análise de redes sociais - Aplicação Nos Estudos de transferência da Informação. Revista Ciência da Informação, v. 30, n. 1, p. 71-81, Brasília.

Mazmanian, M.; Orlikowski, W.; Yates, J. (2006). Crackberrys: exploring the social implications of ubiquitous wireless email devices. In: EGOS CONFERENCE, 22, 2006, Bergen, Noruega, Proceedings. Bergen, Noruega.

Martins, G. A.; Theóphilo, C. R. (2009). Metodologia da investigação científica para ciências sociais aplicadas. 2 ed. São Paulo: Atlas.

Mattos, P. L. C. L. (2005). A entrevista não-estruturada como forma de conversação: razões e sugestões para sua análise. Rev. adm. Publica. v. 39(4). pp. 823-847. jul.-ago.

Meireles, F. S. (2016). Pesquisa Anual - Administração de Recursos de Informática - Gvcia Centro de Tecnologia de Informação Aplicada da FGV-EAESP, 27. ed. São Paulo.

Merriam, S. B. (1998). Qualitative Research and Case Study Applications in Education. Revised and Expanded from "Case Study Research in Education". Jossey-Bass Publishers, San Francisco. 
Mick, D.; Fournier, S. (1998). Paradoxes of technology: consumer cognizance, emotions and coping strategies. Journal of Consumer Research, v. 25, n. 20, p. 123-143.

Miranda, G. J.; Lemos, K. C. S.; Pimenta, A. S. De O.; Ferreira, M. A. (2015). Determinantes do desempenho acadêmico na área de negócios. Revista Meta: Avaliação, v. 7, n. 20, p. 175-209, maio/ago.

Moura, A. (2009). Geração Móvel: um ambiente de aprendizagem suportado por tecnologias móveis para a "Geração Polegar". Recuperado em 03 de agosto de 2016, de http://adelinamouravitae.com.sapo.pt/gpolegar.pdf.

Oliveira, D. de L.; Simões, L. do N.; Silvestre, R. P. (2016). Uso da TI móvel na universidade: análise das percepções e impactos no desempenho discente. EnEPA: Gestão e Sustentabilidade na Amazônia. Porto Velho.

Penedo, S. R. M. (2015). Tecnologia da Informação - Breve História e Perspectivas. AGAPE do Brasil, 2015. Recuperado em 12 de outubro de 2016, de http://agapedobrasil.com.br/blog/2015/04/28/tecnologia-da-informacao-breve-historiaperspectivas/.

Pressman, R.; Maxim, B. (2016). Engenharia de Software. 8. ed. New York, EUA: McGraw Hill. Rangel, J. R.; Miranda, G. J. (2016). Desempenho Acadêmico e o Uso de Redes Sociais. Sociedade, Contabilidade e Gestão, v. 11, n. 2, p. 139-154.

REDAÇÃO, Olhar Digital. (2016). Google Play finalmente supera a App Store em número de aplicativos. Olhar Digital. Recuperado em 12 de outubro de 2016, de http://olhardigital.uol.com.br/noticia/google-play-finalmente-supera-a-app-store-em-numerode-aplicativos/46298.

Saccol, A. I. C. Z. (2005). A Teoria da Hospitalidade e o processo de adoção de tecnologias da informação móveis e sem fio. Tese (Doutorado em Administração) - Faculdade de Economia, Administração e Contabilidade, Universidade de São Paulo, São Paulo. Recuperado em 12 de outubro de 2016, de doi:10.11606/T.12.2005.tde-13102005-121216.

Saccol, A.; Reinhard, N. (2007). Tecnologias de informação móveis, sem fio e ubíquas: definições, estado-da-arte e oportunidades de pesquisa. Revista de Administração Contemporânea.

Shuler, C.; Winters, N.; West, M. (2014). O Futuro da aprendizagem móvel: implicações para planejadores e gestores de políticas. Unesco, Brasília, 2014.

Silva, E. L.; Menezes, E. M. (2005). Metodologia da pesquisa e elaboração de dissertação. 4. ed. Revista Atual. Florianópolis: Laboratório de Ensino à Distância.

Souza, V. B. P. et al (2016). Rede de colaboração como incremento da produção científica na Universidade Federal de Rondônia. EnEPA: Gestão e Sustentabilidade na Amazônia. Porto Velho.

Squirra, S., Fedoce, R. (2011). A tecnologia móvel e os potenciais da comunicação na educação. Logos, v. 18, n. 2, p. 267-278.

Sparrow, B.; Liu, J.; Wegner, D. M. (2011). Google effects on memory: cognitive consequences of having information at our fingertips. Science, 333. pp. 776-778, 2011.Recuperado em 12 de outubro de 2016, de http://www.uvm.edu/ cmplxsys/wordpress/wp-content/uploads/readinggroup/pdfs/2011/google-effects-on-memory.pdf.

Tomar, M. S. (2007). A entrevista semiestruturada. Mestrado em Supervisão Pedagógica. Universidade Aberta. Recuperado em 12 de outubro de 2016, de http://mariosantos700904.blogspot.com.br/2008/04/entrevista-semi-estruturada.html. 
Yin, R. K. (2010). Estudo de caso: planejamento e métodos. 4. ed. Porto Alegre: Bookman. 